2.

Derecho Administrativo 



\title{
Posicionamiento DOGMÁTICO DE LA ACTIVIDAD CONTRACTUAL de la AdMINISTRaCión DEL Estado
}

[Dogmatic positioning of the hiring activity of the State Adminisration]

\author{
Martín Loo GutiérREZ* \\ Pontificia Universidad Católica de Valparaíso
}

\begin{abstract}
RESUMEN
ABSTRACT

La actividad contractual de la Administración del Estado ha sido un campo fértil para una serie de polémicas de importante significado dogmático. Dichas polémicas se han desarrollado en dos ambientes culturales distintos, fundamentalmente, Alemania y Francia. En ambos países se discutió intensamente sobre la naturaleza de los contratos celebrados por la Administración, aunque las discusiones presentan profundas diferencias. Sin embargo, a pesar de tales diferencias, ambas representan un

The contract concluded by the public administration has seen a number of controversies of very important dogmatic relevance. These controversies arose in diverse cultural environments, mainly Germany and France. In both countries there was intense discussion over the legal nature of administrative contracts. Notwithstanding the deep differences these discussions present, both represent a relevant work of doctrine and courts decisions to identify what is the kernel of the administrative law speciality.
\end{abstract}

Recibido el 1 de noviembre de 2017 y Aprobado el 12 de mayo de 2018

* Doctor en Derecho por la II Università di Roma Tor Vergata. Profesor asociado de derecho administrativo. Pontificia Universidad Católica de Valparaíso. Dirección Postal: Avenida Brasil 2950, Valparaíso; dirección electrónica: martin.loo@ pucv.cl. Investigación realizada en el ámbito del proyecto Fondecyt de Iniciación N.o 111160169. Agradezco las agudas observaciones del abogado Eduardo Bustamante Sánchez a un borrador de este trabajo. 
esfuerzo doctrinal o jurisprudencial por identificar el núcleo de la especialidad administrativa.

\section{Palabras Clave}

Contratos administrativos Dogmática jurídico-administrativa - Derecho administrativo comparado - Derecho administrativo francés Derecho administrativo italiano.

\section{KeY WORDS}

Administrative Contracts Administrative Law Doctrine Comparative Administrative Law French Administrative Law - Italian Administrative Law.

\section{INTRODUCCIÓN}

Una de las temáticas fundamentales de la parte general del derecho administrativo trata sobre aquella especie de actividad formal (o jurídica) de la Administración del Estado que suele denominarse "contratación administrativa". Ella comprende el análisis de la actividad de relación con terceros que la Administración Pública desarrolla recurriendo al módulo consensual, esto es, renunciando a la imposición unilateral y ejecutoria de sus decisiones. Se trata, en definitiva, del estudio de los acuerdos que, con distintas finalidades y objetos, la Administración del Estado celebra con particulares ${ }^{1}$.

El estudio de dicho capítulo del derecho administrativo prevé, de modo irrenunciable, el análisis -más, o menos, detallado- de dos argumentos: el primero se refiere a la discusión sobre la plausibilidad de que la Administración del Estado, en su calidad de poder público, alcance acuerdos con los particulares; el segundo, por su parte, corresponde al estudio de la diferencia existente entre los "contratos administrativos" y los "contratos de derecho privado de la Administración", es decir, al análisis de las condiciones y requisitos que deben presentarse para la aplicación de un régimen jurídico particular y distinto del estatuto de derecho común a un cierto grupo de contratos celebrados por la Administración denominados, precisamente, "contratos administrativos".

Son dos temáticas claramente distintas, fácilmente diferenciables y que atienden a problemas dogmáticos tan diversos que, incluso se ha señalado,

${ }^{1}$ Con esto, se excluye del ámbito de esta reflexión la actividad administrativa consensual que involucra a los mismos órganos administrativos, esto es, aquello que la doctrina denomina convenios interadministrativos y que, a causa de las diferencias que presentan con los acuerdos celebrados con los particulares, no pueden ser abordados en esta oportunidad. 
se trata de argumentos sin conexión mutua ${ }^{2}$. La primera (es decir, la discusión sobre la plausibilidad de la contratación pública) busca establecer si determinadas hipótesis de, al menos en principio, “acuerdos" entre la Administración y un particular son efectivamente contratos. La segunda (esto es, la distinción de disciplinas jurídicas aplicables a los distintos 'tipos' de contratos celebrados por la Administración), busca determinar los criterios e, idealmente, el criterio sobre cuya base resulte posible discriminar el régimen jurídico aplicable a dichos distintos tipos de contratos.

Ambas temáticas se cuentan entre los temas clásicos del derecho administrativo general y, no obstante las diferencias apenas indicadas, según mi opinión, tienen en común una cuestión que se demuestra como de la mayor relevancia. Dicho común denominador es el contexto en el cual se colocan en cuanto discusiones dogmáticas, el cual no es otro que la fatigosa tarea de consolidación de la autonomía científica del derecho administrativo frente al mucho más desarrollado derecho civil. En buenas cuentas, se trata de dos discusiones que ocuparon de manera relevante a la naciente ciencia del derecho administrativo, allá por fines del siglo XIX y comienzos del XX, época en la cual los iuspublicistas asumieron la tarea de buscar los instrumentos dogmáticos que permitieran afirmar de modo definitivo la (cuestionada) especialidad de esta área del derecho público y adquirir la dignidad de rama autónoma dentro de la ciencia jurídica.

Tal tarea, en aquella parte de Europa que vivió la polémica acerca de la plausibilidad de los "contratos de derecho público" (principalmente, Alemania y Austria), fue acometida fundamentalmente por la doctrina. Por su lado, la construcción del criterio que permitiera distinguir al contrato administrativo del contrato privado de la administración fue una problemática que se desarrolló con especial fuerza en Francia y España y cuya resolución fue una misión compartida por la jurisprudencia y la legislación ${ }^{3}$.

A la luz de lo anterior, hoy resulta interesante intentar dar una mirada

${ }^{2}$ Martín-Retortillo Baquer, Sebastián, La institución contractual en el derecho administrativo: en torno al problema de la igualdad de las partes, en Revista de Administración Pública 29 (1959), p. 61.

${ }^{3}$ De este modo, MeILÁN GIL, José Luis, Un meeting point de los ordenamientos jurídicos sobre contratación pública en Revista de Administración Pública 198 (2015), p. 44, sostiene que "en el tema contractual puede constatarse una retroalimentación de doctrina con jurisprudencia y legislación de lo que es paradigmático el caso francés y, en su órbita, el español y muchos latinoamericanos". La comparatística también traza esta línea divisoria entre las tradiciones alemana y austriaca, por una parte y la francesa y española, por otra. Véase al respecto LANGROD, Georges, Administrative contracts: a comparative study en The American Journal of Comparative Law 4 (1955), pp. 347 y 363. Junto a los sistemas ya mencionados, alguna doctrina española identifica en Italia un tercer sistema que comparte algunas características propias del sistema alemán 
con la perspectiva del tiempo a la búsqueda del significado que tuvieron las discusiones recién recordadas, debido a que ellas ponen de manifiesto una tensión siempre presente en nuestra disciplina, esto es, el permanente esfuerzo por romper su vinculación 'genética' con el derecho común. Además, se verá cómo las polémicas dogmáticas, que se abordarán en este artículo, son evidencia de esta 'lucha por existir', librada por el derecho administrativo desde sus orígenes y lo que es más relevante, en cada una de sus instituciones fundamentales ${ }^{4}$.

Dado lo anterior, el presente artículo se estructurará de la siguiente manera: en primer lugar, me referiré a la discusión sobre la plausibilidad de que la Administración celebre contratos con los particulares, es decir, a la discusión teutónica sobre el 'contrato de derecho público' (öffentlichrechtlicher Vertrag) (II). En segundo lugar, intentaré reconstruir la discusión acerca de las razones que se invocaron (y todavía se invocan en nuestras cátedras) para distinguir entre dos clases de contratos celebrados por la Administración, es decir, a la construcción franco-española sobre los 'contratos administrativos' (contrat administratif) (III). Finalmente, a modo de conclusión, buscaré conectar estas dos discusiones con la cuestión más general relativa al difícil proceso de adquisición de la autonomía por parte del derecho administrativo (IV).

\section{II. “LA ADMINISTRACIÓN NO CONTRATA, ORDENA"}

En primer lugar, se deben analizar los términos en que se verificó la discusión sobre la posibilidad de que la Administración del Estado, en cuanto poder público, alcance acuerdos con los particulares. La cuestión fundamental de este punto puede presentarse de un modo bastante expedito por medio de la siguiente pregunta: ¿es admisible que la Administración Pública contrate con los particulares?

Antes de abordar el argumento resulta necesario realizar una precisión en cuanto a cómo se ha entendido la temática por parte de la doctrina nacional.

En nuestro medio se ha aceptado sin mucha polémica la posibilidad de que la Administración celebre contratos para el cumplimiento de los fines que el ordenamiento le ha prefijado. En efecto, la doctrina nacional

y del sistema franco-español. En este sentido, véase Martín-Retortillo Baquer, Sebastián, La institución... cit. (n. 2), p. 62.

${ }^{4}$ En este sentido se expresa, aunque referido únicamente al instituto del contrato de la administración y a su 'Existenzkampf, Martín-Retortillo BaQUer, Sebastián, La institución... cit. (n. 2), p. 72. 
es unánime al sostener que la Administración puede emplear la técnica contractual para alcanzar la satisfacción del interés general ${ }^{5}$.

De esta forma, en nuestro medio no existe cuestionamiento alguno acerca de la habilitación con que cuenta la Administración para contratar con un empresario la construcción de una autopista o de un edificio, celebrando un contrato de obra pública; adquirir bienes muebles para el funcionamiento de sus dependencias, por medio de un contrato de suministro, o bien, convenir con una empresa el servicio de vigilancia de un local ocupado por un organismo de la Administración, a través de un contrato de prestación de servicios, etc. ${ }^{6}$. Tales actuaciones de la Administración se encuentran destinadas a satisfacer el interés general, su realización resulta perfectamente admisible y no hay duda alguna de que su naturaleza es contractual. Por lo demás, nuestra legislación deja poca duda acerca de la habilitación que se confiere a la Administración para concluir estos contratos. A este efecto, basta recordar la Ley de Compras Públicas, donde se regulan los contratos de suministros y de prestación de servicios, o la Ley Orgánica del Ministerio de Obras Públicas, y sus cuerpos legales y reglamentos complementarios, donde se disciplinan el contrato de obra pública y el de concesión de obra pública, entre otros cuerpos normativos que se refieren a la actividad contractual de la Administración.

Por tanto, la posibilidad que tiene la Administración del Estado de celebrar esta clase de actos jurídicos no puede ser cuestionada en nuestro país: la doctrina siempre ha sostenido que la Administración requiere y necesita la conclusión de negocios jurídicos que le permitan entrar en relaciones de orden patrimonial con aquellos particulares interesados en prestar servicios o vender bienes a la administración; y la legislación, por su lado, es explícita al conferir competencia para la celebración de contratos.

Establecido el hecho que nuestra doctrina acepta sin reparos que la Administración Pública chilena celebra contratos (y que aquello que celebra

${ }_{5}$ Así, por ejemplo, OelcKers Camus, Osvaldo, En torno al concepto de contrato administrativo en Revista de Derecho Pontificia Universidad Católica de Valparaíso 3 (1979), p. 147, donde se sostiene que "a la Administración nada le prohíbe la posibilidad de celebrar estos contratos, al contrario es una fórmula de cooperación del particular a la satisfacción de necesidades públicas..."; Sото KLOSs, Eduardo, $\mathrm{La}$ contratación administrativa: un retorno a las fuentes clásicas del contrato (a propósito de la distinción contrato administrativo/contrato civil de la Administración), en Revista de Administración Pública 86 (1978), p. 583: "si toda la actuación de la Administración está finalizada por el derecho a la obtención del bien de la comunidad, también lo está su actividad jurídica, y no sólo unilateral (donde nadie duda), sino obviamente su actividad jurídica contractual".

${ }^{6}$ Bermúdez Soto, Jorge, Derecho Administrativo General (3a ed., Santiago, LegalPublishing, 2014), pp. 235-236. 
son, precisamente, contratos y no otra especie de acto), debe recordarse que esta misma doctrina, al momento de exponer la problemática del contrato administrativo recurre con frecuencia a la polémica alemana sobre la admisibilidad del contrato de derecho público.

En este sentido, Oelckers sostiene que: "la realidad jurídica es que la Administración contrata y que en Derecho Administrativo, el Contrato Administrativo es una realidad. En Alemania, donde se duda de la existencia de él, Forsthoff nos dice que negar el Contrato Administrativo es negar esa realidad"7. Luego, el mismo autor, a fin de dar cuenta de la discusión suscitada, agrega que: "se dice [acerca de los contratos], o que se trata de contratos privados que celebra la Administración como cualquier particular, o se trata de actos administrativos unilaterales necesitados de aceptación para su eficacia”. Esta ha sido fundamentalmente la postura de la doctrina alemana bajo la influencia de Otto Mayer ${ }^{8}$.

Estas opiniones se encuentran también en doctrina más cercana en el tiempo. Por ejemplo, se sostiene que la tesis desarrollada por Otto Mayer en su trabajo "Sobre la teoría del contrato jurídico público" correspondería a una "negación del contrato administrativo" que hoy se encuentra totalmente superada? .

Puede verse que en nuestro entorno, se ha consolidado la siguiente idea: la problemática inicial de la construcción teórica del contrato administrativo es que hubo una parte de la doctrina alemana (hoy día superada) que inicialmente negó la posibilidad de que la Administración celebrara contratos. De ello se seguiría que la pregunta fundamental que cabe formular dice relación con la posibilidad o imposibilidad de que la Administración concluya contratos.

Como se intentará poner de relieve en este apartado, tal comprensión de la problemática es, al menos parcialmente errada; ya que el problema enfrentado por la doctrina alemana es diverso.

En efecto, la discusión que se desarrolló desde fines de la década de 1880 y hasta bien entrada la década de 1920, se centró en una problemática específica y distinta que no se relaciona con la posibilidad de que la Administración celebre contratos, sino que en el análisis de la naturaleza jurídica de ciertas hipótesis en las cuales los efectos de determinadas decisiones del Estado, para producirse, parecen necesitar de la colaboración de

7 Oelckers Camus, Osvaldo, En torno... cit. (n. 5), p. 138.

${ }^{8}$ Ibid. pp. 138-139.

9 Moraga Klenner, Claudio, Contratación administrativa (Santiago, Editorial Jurídica de Chile, 2007), p. 31. El trabajo referido por el autor es aquel de MAYER, Otto, Zur Lehre vom öffentlich-rechtlichen Vertrage, en Archiv für öffentliches Recht 3 (1888), pp. 3-86, sobre el cual deberemos ocuparnos en lo sucesivo. 
la voluntad del destinatario de tales decisiones. Una parte de la doctrina calificó dichos supuestos como 'contratos de derecho público'. Otra negó tal calidad.

Por tal razón, cabe advertir que la discusión que nos aprestamos a describir en sus rasgos fundamentales no dice relación con los contratos administrativos sino que con los contratos de derecho público.

Esta aclaración terminológica es extremadamente relevante toda vez que sintetiza el objeto central de la polémica que no solo en nuestro entorno ha sido trasladada, en modo erróneo, al ámbito propio de los contratos de la Administración. En efecto, como lo sostiene la doctrina española, la discusión alemana sobre esta temática pertenece más propiamente al derecho constitucional (o, como quiera que sea, al derecho del Estado o Staatsrecht) antes que al derecho administrativo ${ }^{10}$.

La polémica, en su forma inicial, vio enfrentados a dos de los más importantes profesores alemanes de derecho público y administrativo, Paul Laband y Otto Mayer, y se inicia a propósito de la calificación como 'contratos de derecho público' que Laband dedica a la adquisición por parte del extranjero de la nacionalidad (Naturalisation) y el establecimiento de la relación funcionarial (Beamtenanstellung) ${ }^{11}$. De acuerdo con Laband, ambas serían hipótesis de contratos de derecho público ${ }^{12}$.

El problema que se planteó la doctrina dice relación con el rol que cumple la voluntad del sujeto privado en las hipótesis antes indicadas. Así, en el caso de la naturalización, la declaración formulada por el extranjero tendría como función manifestar su intención de someterse al poder del Estado respecto del cual se pretende adquirir la ciudadanía: el contrato de derecho público que se identificaba en esta situación tendría por objeto hacer surgir el status de ciudadano. En el caso de la relación funcionarial, la voluntad del sujeto era vista como un antecedente que funda una relación de sujeción especial, en virtud de la cual el ciudadano que ingresa al servicio de la Administración admite una supremacía de la Administración Pública, reforzada a su respecto ${ }^{13}$.

${ }^{10}$ Martín-Retortillo Baquer, Sebastian, La institución... cit. (n. 2), p. 68.

${ }^{11}$ Huergo Lora, Alejandro, Los contratos sobre los actos y las potestades administrativas (Madrid, Civitas, 1998), p. 120; LEDDA, Franco, Il problema del contratto nel diritto amministrativo (Contributo ad uno studio dei c.d. contratti di diritto pubblico) (Torino, Giappichelli, s/d), p. 9.

${ }^{12}$ Laband, Paul, Das Staatsrecht des Deutschen Reiches (Tübingen, Laupp, 1876), I, p. 167, en lo que respecta a adquisición de la ciudadanía y Laband, I, p. 404, en lo relativo a la asunción del dependiente público.

${ }_{13}$ Véase nuevamente, LedDA, Franco, Il problema del contratto... cit. (n. 11), pp. 10-13. 
Según Laband, en ambos casos, el consentimiento del particular da lugar a un contrato entre dicho particular y el Estado, toda vez que la voluntad del ciudadano resulta imprescindible para dar lugar al efecto jurídico que se pretende alcanzar. Por esta razón y ya que el objeto del acuerdo se refiere a materias propias del derecho público, según Laband, estas hipótesis no podrían sino ser calificadas como Staatsrechtlichen Vertrage (contratos de derecho público $)^{14}$.

La explicación de Laband para alcanzar estas conclusiones es relevante para los fines de este artículo. La argumentación, de acuerdo con Huergo, se desenvuelve del siguiente modo: si nadie discute que el Estado contrata con los particulares para la adquisición de bienes y servicios (contratos regidos en Alemania por el derecho privado), ¿por qué la misma persona no puede recurrir al contrato también en Derecho público? Mejor dicho, ¿por qué no se puede llamar contrato a relaciones en las que se da la misma característica (es decir, que la producción de un efecto jurídico está condicionada a la voluntad de ambas partes), solo porque nos encontremos en el campo del Derecho público? ${ }^{15}$.

El cuadro de referencia queda, entonces, delineado del siguiente modo: para Laband existen ciertos supuestos cuyos efectos jurídicos (de derecho público) solo pueden explicarse a causa del consentimiento que se forma entre el particular y el Estado. En tales casos se está en presencia de un contrato que tiene por partes al particular y al Estado, un objeto propio del derecho público y que queda, por ello, regido por este. Como se ve, la única explicación de los efectos jurídicos de las hipótesis estudiadas por Laband es 'tomada en préstamo' desde el derecho privado: el contrato. Y aquí radicará, como tendremos oportunidad de ver enseguida, la crítica de Otto Mayer a la construcción 'contractualista' de Laband.

Ahora bien, cabe recordar que la polémica sobre el contrato de derecho público encuentra su inicio en la crítica formulada por Laband en la recensión al volumen Theorie des französischen Verwaltungsrecht, publicado por Mayer en $1886^{16}$. En dicha recensión (y esto es relevante) Laband

${ }^{14}$ Huergo Lora, Alejandro, Los contratos sobre los actos... cit. (n. 11), pp. 124125.

15 Ibíd., p. 124.

${ }^{16}$ Laband, Paul, Rezension - Theorie des französischen Verwaltungsrechts, en Archiv für öffentliches Recht, 2 (1887), pp. 149-162. Véase también SORDI, Bernardo, Tra Weimar e Vienna. Amministrazione pubblica e teoria giuridica nel primo dopoguerra (Milano, Giuffrè, 1987), pp. 129 ss. quien reconstruye la polémica en la perspectiva de su significación teórica. En un contexto histórico más amplio, la temática viene desarrollada también en Mannori, Luca - Sordi, Bernardo, Storia del diritto administrativo (4a ed., Roma-Bari, Laterza, 2006), pp. 386-392. 
desarrolla una crítica a la obra de Mayer que se concentra en reprochar su pretensión de separar al derecho administrativo y su ciencia del seno del Staatsrecht, de dar autonomía a algo que carecía de un propio objeto de estudio, como el derecho administrativo.

En efecto, en su recensión Laband llega a señalar que el derecho administrativo no es un específico tipo de derecho ${ }^{17} \mathrm{y}$, por lo tanto, que no hay alguna posibilidad de construir una ciencia autónoma que lo estudie porque falta el objeto de tal ciencia, esto es, el derecho administrativo como específica forma del derecho. Para Laband, en suma, no existe necesidad de un derecho especial y distinto que analice y estudie únicamente a la Administración Pública porque todos los problemas derivados de la juridización de su actuar encuentran una adecuada resolución dentro del Staatsrecht ${ }^{18}$.

Estas críticas a su Theorie constituyen el origen del ensayo con el cual Mayer sintetiza su posición polémica frente a los contratos de derecho público. Nos referimos al artículo publicado en 1888, en el número siguiente de la misma revista que había dado cabida a la recensión de Laband, con el cual se hace cargo de responder a la críticas recibidas por su obra ${ }^{19}$.

Es este artículo el que le ha valido a Mayer la etiqueta de 'anticontractualista', que lo acompaña hasta nuestros días. En efecto, como indica la doctrina, "Mayer ha tenido una enorme influencia en el devenir del contrato de Derecho público. Se le cita siempre, e interpreta el papel, un tanto cargado de maniqueísmo, de negador de la categoría" ${ }^{20}$.

El artículo de 1888, entonces, tiene como objeto primordial dar respuesta a las críticas de Laband demostrando que, al contrario de cuanto sostenido por este, existen suficientes motivos para considerar la actividad de la Administración como objeto de una específica rama del derecho público. La argumentación se articula, precisamente, sobre el análisis de aquellas hipótesis en las que Laband identificaba un contrato de derecho público, explicación en la que Mayer identifica la razón por la cual la doctrina iuspublicista de su tiempo era incapaz de reconocer la especificidad de la materia administrativa, ciega a la existencia de aquello que (según Mayer) es el elemento distintivo de esta área del derecho público,

${ }^{17}$ Laband, Paul, Das Staatsrecht... cit. (n. 12), p. 155: "Verwaltungsrecht ist nicht eine spezifische Art von Recht”.

${ }_{18}$ Fioravanti, Maurizio, Otto Mayer e la scienza del diritto amministrativo, en Rivista Trimestrale di Diritto Pubblico, (1983), pp. 612-613.

${ }^{19}$ MAYER, Otto, Zur Lehre vom öffentlich-rechtlichen Vertrag, en Archiv für öffentliches Recht 3 (1888), pp. 3-86. Fioravanti califica este artículo como verdadera 'réplica' a las críticas labandianas: Fioravanti, Maurizio, cit. (n. 18), p. 614.

${ }^{20}$ Huergo Lora, Alejandro, Los contratos sobre los actos... cit. (n. 11), pp. 125126. 
el comando unilateral (Befehl) y, por el contrario, proclive a recurrir a instituciones del derecho privado para explicar fenómenos propiamente administrativos: el mejor ejemplo de esto es, precisamente, el contrato de derecho público.

Entonces, de conformidad con la posición que Mayer construye en el artículo en cuestión, resulta inaceptable y, sin dudas, innecesario tomar en préstamo nociones del derecho privado (el contrato) para explicar instituciones propias del derecho público (la adquisición de la ciudadanía o de la calidad de funcionario del Estado). Para entender los efectos jurídicos que se verifican en estas situaciones, el derecho público no solo es autosuficiente, sino que autónomo, toda vez que cuenta con un elemento característico y propio: la decisión unilateral de la Administración Pública que es capaz de alterar las situaciones jurídicas de sus destinatarios. Tal institución se denomina, como sabemos, acto administrativo.

De este modo, Mayer busca demostrar que los contratos de derecho público no son verdaderos contratos en el sentido que el derecho privado atribuye al término, esto es, acuerdos que regulan las relaciones de dos sujetos que se encuentran en situación de paridad y que nacen del común entendimiento entre los mismos. Por el contrario, en opinión del autor, la esencia típicamente autoritativa de la Administración se transmite también y necesariamente a todos los ámbitos de su actividad jurídica haciendo imposible prefigurar una categoría de actuación del Estado cuyo nacimiento o existencia se encuentre condicionado al consentimiento del particular. En otras palabras, Mayer busca explicar el fenómeno que Laband califica como contrato de derecho público desde una perspectiva exclusiva y rigurosamente unilateral y ello porque buscaba "combatir el tradicional dominio del derecho privado" en el ámbito del derecho público ${ }^{21}$.

Entonces, el artículo de 1888 puede ser leído como un primer esfuerzo sistemático y serio por publificar el derecho administrativo, dándole autonomía frente al todopoderoso derecho civil. Como tal, el esfuerzo se avale del derecho administrativo francés y, específicamente, de una de sus creaciones más características, el contrat administratif. Al efecto, Mayer sostiene que el mal llamado 'contrato' de derecho público no es tal porque es radicalmente distinto del contrato de derecho privado. Ello porque la característica esencial del 'contrato' de derecho público no es otra que ser "del lado del Estado [...] un acto administrativo"22. Entonces, según Mayer, estos mal llamados 'contratos' son, en realidad, un pronunciamiento

${ }^{21}$ Fioravanti, Maurizio, Otto Mayer... cit. (n. 18), p. 616.

${ }^{22}$ MaYer, Otto, Zur Lehre... cit. (n. 19), p. 23: "Der öffentlichrechtliche Vertrag, contrat administratif, ist von Seiten des Staates ein Verwaltungsakt”. Se debe hacer notar que Mayer formula una sinonimia entre el contrat administratif y el 
autoritativo de la Administración Pública que se funda exclusivamente sobre la competencia del sujeto del cual emana. De esto se sigue que toda la vida de la relación subyacente a dicho 'contrato' no es regulada por el encuentro de voluntades de sus partes, sino que por una serie de actos unilaterales de la Administración, que vinculan directamente a la contraparte y que configuran su esfera de derechos y obligaciones ${ }^{23}$, tal como ocurre con el contrat administratif del derecho francés.

¿Cómo explica Mayer, entonces, aquello que Laband identifica como una manifestación de la contractualidad del Estado? ¿Dónde se debe situar la inevitable participación del consentimiento del particular que estas hipótesis requieren para surtir sus efectos?

El profesor de Estrasburgo, poniendo énfasis en el momento autoritativo, sostiene que los efectos jurídicos que surgen de la naturalización del extranjero y la asunción del empleado público se explican, únicamente, como consecuencia de la sumisa aceptación por parte del sujeto privado de la decisión de la Administración Pública en orden a naturalizarlo o a incorporarlo a los rangos de la Administración como funcionario del Estado. Para Mayer, dichos efectos no nacen del acuerdo entre el ciudadano y el Estado, sino que exclusivamente de la decisión unilateral del segundo que es aceptada por el primero. Nace así la famosa figura del acto administrativo en virtud de sumisión (Verwaltungsakt auf Unterwerfung) ${ }^{24}$.

De acuerdo con Mayer, no es necesario recurrir a una noción propia del derecho privado para explicar el surgimiento de los efectos jurídicos en aquellas hipótesis en las cuales Laband ve un contrato de derecho público. Para Mayer resulta insostenible que se deba atribuir a una categoría civil -el contrato- la tarea de expresar la presencia de los necesarios elementos consensuales y que se asigne a esta figura del derecho privado la misión de dar vida a una relación de sujeción especial. Por esta razón, la intención de Mayer es afirmar la naturaleza únicamente pública (o unilateral) de las hipótesis en cuestión.

Ello es así porque, siendo el derecho administrativo una rama autónoma y perfectamente identificable dentro del derecho público, no le resulta necesario tomar 'prestadas' categorías del derecho privado para explicar sus propios fenómenos, que pueden ser comprendidos utilizando su propio

öffentlich-rechtliche Vertrag que, como veremos enseguida, tendrá una incidencia fundamental en la comprensión de su elaboración.

${ }^{23}$ Fioravanti, Maurizio, Otto Mayer... cit. (n. 18), pp. 616-617.

${ }^{24}$ Construcción teórica que es calificada de 'retorcida' y a la cual se asigna la onerosa tarea de expresar la 'centralità pubblicistica del provvedimento come manifestazione imperativa della volontà dell'amministrazione'. Así Sordi, Bernardo, The Weimar... cit. (n. 16), pp. 137-138. 
instrumental dogmático. Entre tales herramientas juega un papel central la noción de autoridad de la cual el Estado se avale para manifestar su decisión, la cual terminará siendo aceptada por el particular destinatario de la misma. Es por ello que en la comprensión mayeriana, la manifestación de voluntad del privado se mantiene completamente ajena al nacimiento de la relación cuyo surgimiento, por el contrario, es realización concreta del poder estatal ${ }^{25}$.

En este esquema, la voluntad del particular adquiere un significado secundario: podría decirse que se trata de una condición de eficacia y no una condición de existencia del acto, el cual surge en virtud del poder de la Administración y no gracias al consentimiento del súbdito. En efecto, la doctrina indica a este respecto que la finalidad de la construcción mayeriana es constreñir el elemento consensual en un esquema que lo haga completamente accesorio a la manifestación de voluntad administrativa ${ }^{26}$. La participación de la voluntad del administrado, entonces, se posiciona simplemente como "hecho jurídico sustitutivo de la disposición legal habilitante" 27 , que permite a la Administración contar con la potestad suficiente para 'obligar' a un sujeto a adquirir la nacionalidad o desempeñarse como funcionario del Estado.

A la luz de cuanto dicho, puede afirmarse que, para Mayer, la explicación labandiana era insostenible: los efectos jurídicos en estas hipótesis no se concretan como resultado de un acuerdo entre el Estado y el particular, sino que como consecuencia de la sumisión con que el particular acepta a su respecto una decisión unilateral de la autoridad administrativa; acá no hay 'acuerdo de voluntades', hay simplemente sumisión a una determinación unilateralmente adoptada por el detentor del poder estatal.

¿Por qué razón Mayer niega que pueda haber un acuerdo entre el Estado y el administrado? Más allá de las razones de tipo sistemático -que tendremos oportunidad de retomar más abajo- Mayer sostiene que la relación jurídica de derecho público se encuentra caracterizada por la desigualdad de los sujetos que intervienen en ella $^{28}$, motivo por el cual no existen reglas que determine los derechos y deberes del súbdito (al modo en que el derecho civil determina los derechos y deberes de las partes de un contrato), razón por la cual la relación que surge entre el Estado y el administrado no puede, en caso alguno, calificarse como contrato, puesto

${ }^{25}$ LEDDA, Franco, Il problema del contratto... cit. (n. 11), p. 18.

${ }^{26}$ Sordi, Bernardo, The Weimar... cit. (n. 16), p. 134.

${ }^{27}$ LEDDA, Franco, Il problema del contratto... cit. (n. 11), p. 18.

${ }^{28}$ MaYer, Otto, Zur Lehre... cit. (n. 19), p. 52: "Ungleichheit der beiden Rechtssubjecte". 
que es radicalmente distinta a dicha institución, precisamente, a causa de la desigualdad de los sujetos ${ }^{29}$.

De esta manera, en la doctrina de Mayer, el contrato (de derecho público) resulta incompatible con el ejercicio del poder administrativo y con la naturaleza pública del bien o de la actividad a la cual se pretende aplicar su disciplina. En razón de ello, el contrato debe salir de escena y ceder su lugar a la soberanía, a la autoridad, en otras palabras, al acto (administrativo) unilateral que, en consecuencia, debe ser considerado el instrumento típico y exclusivo de la actividad administrativa ${ }^{30}$.

En este punto, entonces, resulta necesario retomar nuestra pregunta inicial: ¡es correcto afirmar que Mayer negó in toto la capacidad contractual de la Administración, como ordinariamente se afirma? La respuesta es necesariamente negativa.

Aquello que Mayer niega es que deba recurrirse al contrato (de derecho público) para explicar hipótesis que admiten una comprensión enteramente publicística, como lo son la adquisición de la ciudadanía o de la calidad de funcionario público. Mayer no niega, sin embargo, la capacidad de derecho privado de la Administración, la cual le permite celebrar contratos con aquellos particulares que le suministrarán bienes muebles o que construirán las obras públicas necesarias para el funcionamiento de sus órganos o para el uso por parte de la población. Tanto es así que en países que se alinearon a favor de posiciones 'anticontractualistas', como Italia, la doctrina afirma que es completamente indiscutible que la Administración Pública pueda encontrarse vinculada por un contrato resultante de la manifestación de voluntad expresada por una autoridad administrativa que se funde con la voluntad manifestada por privados. Esta noción no está en discusión si se refiere a la llamada "actividad privada de la Administración", esto es, aquella destinada a procurarse bienes y servicios ${ }^{31}$. En otras palabras, ni la doctrina de aquellos países donde se negó la posibilidad del contrato de derecho público, ni Mayer en particular, han desconocido que la Administración pueda celebrar contratos. Dichos contratos, sin embargo, quedarán regidos por el derecho privado ${ }^{32}$.

${ }^{29}$ Fioravanti, Maurizio, cit. (n. 18), p. 618; LeDdA, Franco, cit. (n. 11), p. 19; STOLleIs, Michael, Storia del diritto pubblico in Germania, 1800-1914, (trads.) Cristina Ricca y Stefano Pietropaoli (Milano, Giuffrè, 2014), p. 614.

${ }^{30}$ SORDI, Bernardo, Pubblica amministrazione, negozio, contratto: universi e categorie ottocentesche a confronto, en Diritto Amministrativo (1995), pp. 505-506.

${ }^{31}$ Virga, Pietro, Contratto (dir. amm.), en Enciclopedia del Diritto (Milano: Giuffrè, 1961), IX, pp. 979-980.

32 Sordi, Bernardo, Pubblica amministrazione... cit. (n. 30), p. 484: "Non si è mai negato, certo, neppure nel secolo scorso, che l'amministrazione possedesse 
Mayer, en efecto, no niega ni discute que la Administración goce de esta capacidad de celebrar contratos con los particulares, pero se trata de negocios patrimoniales que ella realizará en ejercicio de su capacidad de derecho privado y ya no como sujeto detentor del poder público; se trata de contratos cuyo objeto, se podría decir, es de naturaleza privada, como la adquisición de bienes muebles o la construcción de obras, razón por la cual trasladar los argumentos aportados por el profesor de Estrasburgo para comprender la problemática de los contratos administrativos (y ya no de los contratos de derecho público) resulta, como se ha dicho al inicio, un error que afecta no solamente a nuestra doctrina y cuya responsabilidad bien podría achacarse al propio Mayer.

En efecto, Mayer, en su artículo, equipara al contrato de derecho público labandiano el contrat administratif del derecho francés que, como se verá a continuación, corresponde a una construcción jurisprudencial y dogmática que atiende a problemas completamente distintos de aquellos que pretendía enfrentar Laband.

$\mathrm{Al}$ respecto se ha sostenido que: es evidente que los autores alemanes que negaban el contrato de derecho público lo hacían con referencia al empleo público y a la adquisición de la nacionalidad, mientras que los franceses, al aceptar el contrato administrativo, no pensaban en la adquisición de la nacionalidad, sino en unos supuestos (obras públicas, servicios públicos), cuya naturaleza contractual reconocía perfectamente Mayer (considerándolos contratos privados) $)^{33}$.

¿De donde surge, entonces, esta 'confusión' entre contratos de derecho público y los contratos administrativos? Como ya se adelantó, el responsable de ella sea, probablemente, el mismo Mayer al haber identificado el contrat administratifdel derecho francés con el öffentlich-rechtlicher Vertrag estudiado por Laband. Si bien, como sostiene la doctrina italiana, entre ambos institutos podría existir una similitud a nivel lingüístico, ellos se encontraban muy distantes en cuanto a significado dogmático ${ }^{34}$.

Como veremos a continuación, el instituto francés del contrato administrativo responde a necesidades de la práctica jurisprudencial que no se avienen bien con la 'utilización' que Mayer hizo de su equivalente

una capacità giuridica di diritto privato: che l'amministrazione esercitasse, cioè, un' «attività di gestione» in cui si stipulano contratti di appalto; si acquistano forniture; si concludono, infine, secondo varie forme convenzionali, negozi economali"; Martín-Retortillo Baquer, Sebatián, La institución... cit. (n. 2), p. 79: "Los supuestos que los derechos francés y español ofrecen como contratos administrativos, se resuelven en el derecho alemán como contratos de derecho privado."

${ }^{33}$ Huergo Lora, Alejandro, Los contratos... cit. (n. 11), p. 160.

${ }^{34}$ Sordi, Bernardo, The Weimar... cit. (n. 16), p. 130. 
lingüístico alemán. Por de pronto, para culminar esta sección, y como ya ha quedado dicho en precedencia, el problema que quiso enfrentar Mayer dice relación con la construcción del campo propio de regulación del derecho administrativo. Enseguida veremos que tales preocupaciones se encontraban muy alejadas de las inquietudes que se quisieron resolver con la elaboración de la teoría sobre el contrat administratif.

\section{El CONTRATO ADMINISTRATIVO FRANCÉS Y LA DEFENSA DE la autonomía de la ADMINISTRation PUbLIQUE}

El problema que pretende resolver la construcción francesa del contrato administrativo dice relación con la aplicación de un estatuto jurídico particular para aquellos contratos que la Administración celebra para procurarse bienes, servicios y obras. La pregunta fundamental en relación con esto es: ¿merece un contrato celebrado por la Administración algún régimen jurídico distinto a aquel de derecho común? La respuesta, en Francia, naturalmente, fue positiva. Aquí interesa indagar el porqué y los criterios que se desarrollaron para formular la distinción.

La institución del contrat administratif, como otras del derecho administrativo francés, se desarrolla gracias al trabajo del Consejo de Estado, el cual, a través de sus decisiones, fue dando un perfil y un régimen propio a un grupo de contratos celebrados por la Administración que, de merecer solo una jurisdicción especial, culminaron teniendo una disciplina jurídica propia y diferente respecto de otros contratos, también celebrados por la Administración, que, sin embargo, continuaron sometidos al derecho y al foro común ${ }^{35}$.

Asimismo, el contrato administrativo en Francia forma parte de aquel grupo de creaciones jurisprudenciales cuyo carácter político resulta difícil de ignorar. Junto al servicio público y al acto administrativo, a la misma jurisdicción administrativa y la doctrina de los actos de gobierno, la comprensión jurisprudencial de la institución contractual demanda una revisión, aunque sea somera, del delicado equilibrio de los poderes

35 En este sentido, Langrod, Georges, Administrative contracts... cit. (n. 4), p. 340, sostiene que "it is in France that, through the creative action of the administrative tribunal, the notion of the administrative contracts have been elaborated, its specific legal regulation conceived and defined”. Además, Jèze, Gastón, Principios generales del derecho administrativo (Buenos Aires, Depalma, 1949), III, p. 312. afirma que "es la jurisprudencia del Consejo de Estado la que, por sus pronunciamientos concretos, ha elaborado paulatinamente y continúa elaborando el régimen jurídico aplicable, no sin vacilaciones, contradicciones y oscuridades. Esta ésta la teoría de los contratos administrativos". 
públicos que se formó inmediatamente después de los hechos de julio y agosto de 1789 .

Como se sabe, una de las primeras medidas legislativas adoptadas por los revolucionarios fue la reafirmación, en términos concretos, del principio de separación de poderes sancionado en el artículo XVI de la Declaración de Derechos del Hombre y el Ciudadano ${ }^{36}$. La defensa extrema de tal principio es la justificación del conocidísimo artículo 13 de la ley del 16-24 de agosto de 1790, sobre la organización judicial que, luego de establecer el principio capital de la separación de la función jurisdiccional de aquella administrativa, sancionaba con la pena de prevaricación a los jueces que 'disturbaren' las operaciones de los cuerpos administrativos o citaren ante ellos a los administradores en razón de sus funciones ${ }^{37}$.

La norma antes citada muestra claramente la importancia que los revolucionarios atribuyeron a la autonomía de la Administración Pública frente a las posibles interferencias provenientes de los órganos judiciales. Por tal motivo, resulta posible afirmar que una de las tareas iniciales de la Revolución fue limitar el poder contrarrevolucionario que podían ejercer los titulares de los oficios jurisdiccionales contra la Administración del Estado.

En esta perspectiva cabe señalar que el principio de división de poderes es interpretado por la Revolución Francesa, fundamentalmente, como un principio puesto en defensa de la autonomía e independencia del poder administrativo frente a los jueces. Dicha defensa se manifestará en términos concretos en las reglas sobre el contencioso, sustrayendo las controversias entre Administración y ciudadanos de las manos del juez ordinario ${ }^{38}$.

Por tal razón, durante los primeros años de la Revolución, la tipología o naturaleza de la actividad administrativa poco importará a la hora de determinar la jurisdicción encargada de juzgarla; bastará que se trate de una actividad realizada por el sujeto Administración Pública para frenar la potestad jurisdiccional de los órganos ordinarios y deferir su conocimiento ante los órganos administrativos encargados del control de sus pares.

Esta finalidad explica claramente la amplitud de la primera noción de acto administrativo elaborada por la doctrina francesa de la época. De acuerdo con dicha definición, desarrollada por Merlin a comienzos del

36 “Una sociedad en la que la garantía de los derechos no está asegurada, ni la separación de poderes determinada, no tiene Constitución”.

37 "Les fonctions judiciaires sont distinctes et demeureront toujours séparées des fonctions administratives. Les juges ne pourront, à peine de forfaiture, troubler, de quelque manière que ce soit, les opérations des corps administratifs, ni citer devant eux les administrateurs pour raison de leurs fonctions".

38 Sordi, Bernardo, Pubblica amministrazione... cit. (n. 30), p. 489. 
siglo XIX, un acto administrativo es "una sentencia, una decisión de la autoridad administrativa, o una acción o un hecho de un administrador en relación con sus funciones" ${ }^{39}$, concepto que engloba con facilidad cualquier actividad -se diría hoy, formal o material- de la Administración Pública.

La amplitud de este concepto tiene una racionalidad político-institucional evidente: cuanto más amplia, mayor sería el ámbito de actividad administrativa que se encontraría sustraída del poder de los jueces. De esta manera, conforme a esta comprensión del acto, toda la actividad subjetivamente administrativa, cualquiera fuera su contenido, se encontraría fuera del alcance de los jueces ordinarios pasando a formar parte del acervo de conflictos sometido a la jurisdicción administrativa.

Entonces, aquello que resultaba relevante respecto de los contratos celebrados por la Administración era afirmar que el contencioso que surgiera de los mismos debía ser conocido por los jueces administrativos y no por los jueces ordinarios. En efecto, como nos enseña Sordi, cuando los antiguos iusadministrativistas formalizaron la noción de acto de la administración, tanto en Francia como en Italia, la primera ejemplificación del mismo se encontrará en los contratos estipulados por la Administración Pública ${ }^{40}$.

Por lo anterior, puede afirmarse que la problemática enfrentada por el contrato en Francia estuvo muy distante de los cuestionamientos que enfrentó en Alemania, una parte de los cuales ya conocemos. El problema del contrato celebrado por la Administración en Francia se relacionó exclusivamente con la necesidad de defender a la Administración y a toda su actividad de la indebida injerencia de los jueces ordinarios.

Progresivamente, como enseña García de Enterría, comenzó a construirse una sistematización más sofisticada de la actividad de la Administración, distinguiéndose de entre los actos 'de la administración', los actos de gestión, por un lado y los actos de autoridad, por otro. En aquellos, la Administración actúa despojada de su imperium y, por dicha razón, el contencioso a que dieran lugar fue restituido al conocimiento de los jueces ordinarios ${ }^{41}$. De esta suerte, tanto las relaciones solamente privadas de la administración, como las relativas a la gestión de su dominio privado y los

39 MerLin, Philippe Antoine, Répertoire universel et raisonné de jurisprudence ( $4^{\mathrm{a}}$ ed., Paris, Garnery, 1812), I, p. 72: “un arrêté, une décision de l'autorité administrative, ou une action, un fait d'un administrateur, qui a rapport à ses fonctions".

${ }^{40}$ SORDI, Bernardo, The Weimar... cit. (n. 16), p. 493.

${ }^{41}$ García de ENTERRÍA, Eduardo, La figura del contrato administrativo en Revista de Administración Pública 41 (1963), p. 101. En igual sentido, Oelckers Camus, Osvaldo, En torno... cit. (n. 5), pp. 139-140. 
contratos no entregados expresamente por la ley al conocimiento del juez administrativo, fueron puestos bajo la competencia del juez ordinario ${ }^{42}$.

$\mathrm{Al}$ respecto, la doctrina agrega que: "el reconocimiento de la categoría de contratos administrativos, como especie dentro del género de contratos que celebra la administración y por oposición a los denominados contratos parcialmente regidos por el derecho privado, surgió en Francia para determinar la jurisdicción competente para entender de los conflictos derivados de ellos" ${ }^{33}$.

Entonces, el cuadro hacia mediados del siglo XIX comienza a delinearse de la siguiente manera: la actividad contractual de la Administración podía encontrarse bajo la jurisdicción tanto del juez ordinario como del juez administrativo. En este último caso, se trataba de los contratos administrativos que habían sido calificados como tales por la ley; en el primer caso, se estará frente a los contratos de derecho privado de la administración.

Cosa curiosa, sin embargo, es que esta distinción no tenía un impacto sobre la disciplina sustantiva que debía regir los diferentes tipos de contrato. $\mathrm{Al}$ respecto la doctrina sostiene que, cualquiera fuera el juez competente, no cabía distinguir entre regímenes jurídicos aplicables al contrato: todos estaban regidos por el derecho privado. Al respecto, García de Enterría indica que "tanto la mens legislatoris como la doctrina, sin la menor excepción, aceptan que la naturaleza de estos contratos cuyo conocimiento se atribuye a la jurisdicción contencioso-administrativa es puramente de derecho civil, cuyas normas materiales serían únicamente las de aplicación [...] de suerte que para el legislador los contratos administrativos suscitaban simples cuestiones de derecho civil que, sin embargo, se atribuían por puras razones prácticas al fuero administrativo" ${ }^{44}$. En otros términos, siguiendo siempre a la doctrina española, los contratos administrativos surgen como contratos sustantivamente civiles de los que, sin embargo, conoce la jurisdicción contenciosa ${ }^{45}$.

Es en este punto que comienza a materializarse la imponente obra creadora de la jurisprudencia del Consejo de Estado en al menos dos sentidos: junto con ampliar el catálogo de los contratos administrativos a algunas hipótesis que no se encontraban expresamente calificadas como tales por la ley y, por ende, a reclamar competencia sobre los mismos, comenzó a

42 Sordi, Bernardo, The Weimar... cit. (n. 16), p. 496.

43 Campolieti, Federico, Los límites del contrato administrativo, en FernándeZ Ruiz, Jorge - Santiago SÁnChez, Javier (eds.), Contratos administrativos. Culturas y sistemas jurídicos comparados (México, Universidad Nacional Autónoma de México, 2007), p. 21.

${ }^{44}$ García de Enterría, Eduardo, La figura ... cit. (n. 41), pp. 101-2.

${ }^{45}$ Martín-Retortillo Baquer, Sebastián, La institución... cit. (n. 2), p. 85. 
elaborar una disciplina especial con diversas modulaciones respecto del derecho común.

De esta forma, la ampliación del catálogo legal de contratos administrativos se realizó por la jurisprudencia a través de la identificación de ciertos elementos distintivos en los contratos que no se encontraban entregados por ley al conocimiento de los jueces administrativos. Tales elementos distintivos fueron la vinculación del contrato con la prestación de un servicio público o bien la presencia de cláusulas exorbitantes. De esta manera, la jurisprudencia comienza a considerar contratos administrativos no solo a aquellos expresamente así calificados por la ley, sino también aquellos otros que contuvieran las recién mencionadas particularidades ${ }^{46}$. Así, la más clásica doctrina francesa define los contratos administrativos señalando que ellos son los contratos "celebrados para asegurar el funcionamiento de los servicios públicos” ${ }^{\prime 7}$.

Por su parte, a partir de la decisión Compagnie Nouvelle du Gaz de Deville-Lès-Rouen, de 1902, la distinción entre contratos administrativos y contratos de derecho privado de la administración dejó de tener una relevancia solo procesal y comenzó a desplegar sus consecuencias en el derecho sustantivo aplicable. En el ârret recién citado, el Consejo de Estado señaló que la flexibilidad del contrato es una necesidad para la buena prestación del servicio público encargado al contratista privado. Con ello admitió que la Administración se encontraba autorizada para modificar unilateralmente el contrato. De esta manera, junto con individualizar el criterio de identificación del contrato (su vinculación con el servicio público), atribuyó consecuencias sustantivas a la calificación del mismo como contrato administrativo, reconociendo su sometimiento a un régi-

${ }^{46}$ Campolieti, Federico, Los limites... cit. (n. 43), pp. 21-22. En igual sentido, De Laubadère, André, Manual de derecho administrativo (Bogotá, Temis, 1984), pp. 185-186, señala que para la identificación de un contrato administrativo es posible echar mano a dos criterios: la calificación legal (que, según la doctrina puede verificarse implícitamente por medio de la atribución de competencia a la jurisdicción contenciosa) y la calificación jurisprudencial, basada en los criterios del servicio público y de la cláusula exorbitante.

${ }^{47}$ JÈZE, Gastón, Los principios... cit. (n. 35), p. 175. El mismo autor agrega más adelante (pp. 312-313) que para que las reglas particulares de los contratos administrativos se apliquen "no basta que se celebre un contrato entre la Administración y un particular, para la prestación de una cosa o servicio. Es preciso, además, que el contrato tenga por objeto asegurar el funcionamiento de un servicio público. Aun no basta este nuevo elemento; es indispensable que las partes contratantes deseen someterse a un régimen jurídico que sale de la órbita del derecho civil, al régimen del derecho público". 
men exorbitante jurídico, manifestado en este caso en la posibilidad de modificación unilateral por la Administración.

Es por ello que, una vez superada la comprensión de la relevancia solamente procesal de la distinción, la doctrina francesa del siglo XX pudo sostener que si los tribunales administrativos son competentes para conocer de los contratos administrativos es porque se trata de aplicar un régimen jurídico especial ya que el carácter esencial de los contratos administrativos es que se someten a un conjunto de reglas especiales ${ }^{48}$.

Entonces, progresivamente, la jurisprudencia administrativa logró elaborar un régimen articulado de reglas especiales para los contratos administrativos, cualquiera fuera el criterio de determinación de tal naturaleza. Este régimen jurídico propio del contrato administrativo pasó a denominarse "régimen exorbitante" y se encontrará compuesto por una serie de privilegios a favor tanto de la parte pública como de la privada: ius variandi, poderes de control, dirección, sanción, interpretación y terminación unilateral anticipada del contrato, por el lado de la Administración; mantenimiento del equilibrio económico contractual, por el lado del contratista ${ }^{49}$.

Como puede verse, el régimen del contrato administrativo es construido en una suerte de contrapunto con el régimen de derecho común. Como indica la doctrina, la cuestión central del contrato administrativo consiste en relacionarlo con el contrato civil cuyos efectos son 'modulados' por la presencia de la Administración Pública, como parte del mismo. Dicha modulación se concreta en el lexema 'cláusulas exorbitantes', que lo son, precisamente, por modificar las reglas del derecho común ${ }^{50}$.

Vemos en el contrato administrativo francés, nuevamente, el tópico crucial de la identidad del derecho administrativo frente al derecho común. De este modo, la jurisprudencia del Consejo de Estado fue construyendo la institución del contrato administrativo como una excepción a las normas comunes, dándole identidad a través de su divorcio con la matriz contractual del Code Civil o, como sostenía Jèze, a los contratos administrativos no se aplican "pura y simplemente las reglas del derecho civil sobre contratos. El Consejo de Estado modifica estas reglas según las necesidades del buen funcionamiento de los servicios públicos" ${ }^{51}$.

Por ello, a la luz de cuanto expuesto tenemos un cuadro más o menos claro de las vicisitudes que debió enfrentar el contrato en el derecho administrativo francés. Resulta evidente, por un lado, que ellas distan mucho

\footnotetext{
48 Jèze, Gastón, Los principios... cit. (n. 35), p. 314.

${ }^{49}$ Campolieti, Federico, Los límites... cit. (n. 43), pp. 22-23.

${ }^{50}$ Meilán Gil, José Luis, Un meeting point... cit. (n. 3), p. 46.

51 Jèze, Gastón, Los principios... cit. (n. 35), p. 177.
} 
del radical escepticismo con que se trató a la institución contractual en el derecho alemán. Pero también resulta claro que las interrogantes que la jurisprudencia enfrentó en Francia en nada se asemejan a las dudas de índole sistemático que intentó despejar Otto Mayer al negarle la condición de contrato a las hipótesis estudiadas por Laband.

La polémica en torno al contrato en el derecho administrativo tiene, sin embargo, elementos comunes en las experiencias alemana y francesa. Ellas se alzan como esfuerzos -jurisprudenciales o doctrinales- de construcción del ámbito propiamente administrativo a partir de la separación del derecho civil.

Estas semejanzas entre experiencias tan notoriamente diversas merecen un análisis separado.

\section{CONCLUSIÓN: EL CONTRATO Y LA AUTONOMÍA CIENTÍFICA}

\section{DEL DERECHO ADMINISTRATIVO}

Como se viene diciendo, tanto la polémica sobre la plausibilidad del contrato como forma que puede adoptar la actuación jurídica de la Administración del Estado como la construcción de la figura del contrato administrativo mos gallicus tienen, junto a las muchas diferencias que se han resaltado a lo largo de este trabajo, un elemento común que necesita ser puesto en relieve. Tal elemento es que ambas teorías (tanto la que niega la capacidad contractual publicística, como la que sostiene que el contrato administrativo es diverso del contrato de derecho común) versan sobre la autonomía del derecho administrativo frente al derecho civil.

En el caso alemán, la polémica entre Laband y Mayer nos muestra como este último, al negar la calidad de contratos de derecho público a las hipótesis así calificadas por Laband, en realidad estaba, por una parte, negando cabida al consentimiento en el ámbito del derecho administrativo $y$, por otra, buscando un criterio sobre el cual fundar el edificio dogmático de un derecho administrativo enteramente 'público', esto es, purificado de las influencias (indebidas, según Mayer) del derecho civil.

En el caso francés, por su parte, aun con la ausencia de dificultades en la aceptación del contrato como modalidad que puede adoptar la actividad administrativa para la satisfacción de los intereses generales, se puede advertir que el régimen jurídico del contrato administrativo, inicialmente indistinto de la regulación del derecho común, fue progresivamente adquiriendo una fisonomía propia gracias a la serie de caracteres que le fueron atribuidos y que se desarrollaron fundamentalmente en contrapunto con el derecho civil.

Por ello, las vicisitudes del contrato administrativo, allá y acá del Rin, 
pueden resumirse con una palabra: pretensión de es pecialidad del derecho administrativo frente al derecho civil.

Es por ello oportuno que se revisen las argumentaciones elaboradas en Alemania y Francia en torno a esta específica materia.

Ya sabemos que la figura de Otto Mayer ganó una posición de relieve en la doctrina iusadministrativa de fines del siglo XIX interpretando el papel de radical negador del contrato dentro del derecho público. Sabemos también que dicha postura escéptica se construyó sobre el cuestionamiento de la calidad de 'contrato' de las hipótesis calificadas como tal por Paul Laband en su obra Das Staatsrecht des Deutschen Reiches (Naturalisation y Beamtenanstellung). Ahora debe esclarecerse la razón que movió a Mayer para elaborar esta posición doctrinal.

Tal razón puede encontrarse explícitamente elaborada por Mayer en su obra mayor, el Derecho administrativo alemán de 1895. Ahí señala que: "trátese ahora de circunscribir el derecho civil a sus límites naturales y de quitarle una cantidad de instituciones jurídicas de las que se había apoderado [...] en perjuicio de esas instituciones, porque ellas no pueden ser bien comprendidas sino ubicadas en la esfera del derecho público”.

Entonces, según Mayer, para entender el verdadero alcance de las ideas que están detrás de esas instituciones que siguen 'prisioneras' del derecho civil como son, precisamente, los contratos administrativos, se debe descartar "completamente el derecho civil de estas instituciones" y proceder a llenarlas "con la idea de poder público" 52.

La opinión de Mayer es clara y se desarrolla con una doble intención. En primer término, con el objetivo de identificar el elemento propiamente público del derecho administrativo, esto es, elaborar una construcción del derecho administrativo que prescinda completamente de sus vinculaciones con el derecho civil. En segundo lugar y como consecuencia de lo anterior, se intentaba desterrar del derecho administrativo cualquier elemento proveniente del derecho privado.

Esta doble tarea se realizó, precisamente, negando que el Estado requiera del consentimiento del particular para hacer surgir los efectos jurídicos de sus determinaciones. Tal consentimiento del particular, en la construcción de Laband, resultaba imprescindible atendida la calificación contractual que daba a las ya mencionadas hipótesis de la adquisición de las calidades de funcionario público o de ciudadano. Ahora bien, como ya sabemos, estas hipótesis, en la dogmática mayeriana, pueden ser explicadas sin necesidad de introducir el factor de la consensualidad toda vez que ellas no

${ }^{52}$ Mayer, Otto, Derecho Administrativo Alemán (trads. Horacio Heredia y Ernesto Krotoschin, Buenos Aires, Depalma, 1949), I, p. 183. 
son sino actos de manifestación de un preciso poder de mando del Estado que, a lo más, requerirá la sumisión del particular para producir sus efectos (Verwaltungsakt auf Unterwerfung).

En otras palabras, en la construcción de Mayer, el contrato es incompatible con el ejercicio y la naturaleza pública del bien o actividad a la cual se pretende extender la disciplina convencional. Es por ello que el contrato debe apartarse y ceder su lugar al acto administrativo, identificado como exclusivo modo de expresión de la actividad administrativa. En buenas cuentas, el contrato debe ser excluido del campo del derecho administrativo porque no puede aceptarse que él sea un instrumento de la actividad administrativa, la cual puede desarrollarse de modo exclusivo sobre la base del Verwaltungsakt, incluso allí donde se requiere del acuerdo del particular, al menos para la producción de los efectos jurídicos del acto ${ }^{53}$.

Es así que, para Mayer, la Administración, en cuanto manifestación del poder soberano del Estado, cuenta con un único instrumento típico de actuación: la orden unilateral. Cualquiera otra herramienta, junto con ser innecesaria, arriesga la desnaturalización del carácter público, esto es, autoritario, del derecho administrativo. Mayer identifica en la rígida supremacía de la autoridad estatal el momento específico y distintivo del derecho público y, por ello, el contrato, en cuanto manifestación típica de un área del derecho fundamentada en principios disímiles, debe ser expulsada de las elaboraciones dogmáticas propiamente administrativas ${ }^{54}$.

Ciertamente toda la polémica sobre el contrato de derecho público no es más que el preludio de una consciente reformulación de las bases del derecho administrativo que Mayer se esforzó de realizar en su trabajo posterior, especialmente, en su Derecho administrativo alemán. En él logra construir una 'parte general' del derecho administrativo, completamente desvinculada de la tradición 'pancivilista' que le precedía y contra la cual Mayer se dirigió con energía, acusándola de ser incapaz de expulsar de sus construcciones al viejo Polizeistaat, con su doble personalidad, pública y privada, con sus relaciones patrimoniales de naturaleza fiscal y, por ende, sometidas al derecho de los privados. Con Mayer el derecho administrativo se libera de las cadenas del derecho civil y se construye sobre la base de un único elemento típicamente público: el acto administrativo.

Es en ese ámbito donde puede encontrarse otra célebre definición dogmática de Mayer: la noción de acto administrativo. En dicha definición, capaz de representar la actividad típica y exclusivamente administrativa, Mayer logra resumir su comprensión sobre el derecho administrativo (auto-

53 Sordi, Bernardo, Pubblica amministrazione... cit. (n. 30), pp. 505-506.

${ }^{54}$ Fioravanti, Maurizio, Otto Mayer... cit. (n. 18), p. 617. 
ridad) y su pretensión de unificación dogmática del mismo en torno a una figura jurídica exclusivamente pública. Y logra ambos fines, concibiendo al acto como la decisión unilateral capaz de establecer lo que el derecho debe ser para el súbdito en el caso concreto ${ }^{55}$.

En suma, el proceso de autonomización y publificación de esta área del derecho se convirtió en una verdadera 'reconstrucción' (Umbildung) del derecho administrativo. La idea sobre la cual se llevó a cabo esta labor de reformulación dogmática no es otra que la de supremacía de la Administración y con ella, el poder de imposición de la misma sobre los súbditos ${ }^{56}$.

En el caso francés, la polémica sobre el contrato administrativo, aun sin alcanzar el grado de dramatismo que presentó en la doctrina alemana, también se centra, en la elaboración de un conjunto de principios y reglas propiamente administrativas aplicables a ciertos contratos de la Administración.

Como se pudo comprobar con anterioridad, el contrato administrativo nace con entera prescindencia de las reglas sustantivas aplicables al mismo. En otras palabras, surge como respuesta exclusivamente jurisdiccional a una inquietud de naturaleza principalmente política: el mantenimiento de la independencia de la Administración del Estado exigió que sus actuaciones fueran mantenidas lejos del alcance de los jueces ordinarios. Una vez que estuvo satisfecha esta inquietud, la jurisprudencia administrativa no advirtió la necesidad de elaborar una disciplina especial que regulara aquellos contratos que, celebrados por la Administración, habían sido puestos en la esfera de sus atribuciones, de modo que, cualquiera fuera el foro competente para conocer de las controversias a que dieran lugar, el derecho sustantivo aplicable sería el derecho civil. Mal que mal, se trataba de contratos.

Solamente cuando se alcanzó una relativa madurez se hizo patente una necesidad dogmática: reunir bajo una elaboración articulada el conjunto de características especiales que la jurisdicción había ido identificando en los contratos celebrados por la Administración que se encontraban sometidos al conocimiento de la jurisdicción administrativa, o sea, los contratos administrativos.

Dicho conjunto de particularidades del contrato se encuentra justificada en la supremacía de la Administración que, cuando contrata, trae consigo un conjunto de prerrogativas que dan lugar a una serie de diferencias pro-

55 "Der Verwaltungsakt ist ein der Verwaltung zugehöriger obrigkeitlicher Ausspruch, der dem Unterthanen gegenüber im Einzelfall bestimmt, was für ihn Rechtens sein soll”. Así, MAYER, Otto, Deutsches Verwaltungsrecht (Leipzig, Duncker \& Humblot, 1895), I, p. 115.

${ }^{56}$ Sordi, Bernardo, The Weimar... cit. (n. 16), p. 49. 
piamente anticontractuales que se insertan en los contratos administrativos y que los diferencian de los contratos de derecho común. Una vez que dicho conjunto de peculiaridades adquiere consistencia y organicidad se puede sostener que el contrato administrativo no es más que la síntesis del conjunto de peculiaridades que la Administración impone en el contrato del cual es parte ${ }^{57}$.

La jurisprudencia, una vez que reconoció que el contrato administrativo era diferente del contrato de derecho común fundamentalmente como consecuencia de la presencia de la Administración como una de sus partes, debió buscar la justificación de tales diferencias. Y dicha justificación, al igual que en el caso alemán con la orden unilateral (Befehl), se encontró en una expresión de elevado significado político: el service public.

De esta manera, la noción sustancial del contrato administrativo que la jurisprudencia francesa va progresivamente desarrollando ancla al servicio público toda la construcción dogmática del contrato administrativo el cual termina siendo aquel contrato que tiene por objeto "asegurar el funcionamiento de los servicios públicos" ${ }^{58}$.

La presencia de este fin de servicio público será también la justificación del conjunto de 'particularidades' que se identifican en los contratos administrativos. Si observamos solo una de tales particularidades, la 'cláusula exorbitante', advertiremos que se la construye en contrapunto con el derecho civil, esto es, como una excepción al régimen de derecho común del cual pretende apartarse.

La cláusula exorbitante representa, en consecuencia, la manifestación de la especialidad del contrato administrativo de frente al derecho privado. Su justificación se encuentra naturalmente en la finalidad que la Administración busca satisfacer con la celebración de contratos con los privados que no es otra que la prestación de un servicio público. Tan consolidado se encontró este criterio que, hacia inicios de los años setenta del siglo pasado, la doctrina francesa podía afirmar que "si había un tema en el derecho administrativo que parecía haber alcanzado, y por largo tiempo, su punto de equilibrio, era el referente al criterio para determinar cuándo estábamos en presencia de un 'contrato administrativo"' el cual era, naturalmente, "aquel que tiene por objeto conferir al cocontratante la ejecución misma del servicio público" así como aquel contrato que "contiene cláusulas exorbitantes del derecho común" 59 .

\footnotetext{
${ }^{57}$ Martín-Retortillo Baquer, Sebastián, La institución... cit. (n. 2), pp. 8485.

58 Jèze, Gastón, Los principios... cit. (n. 35), p. 175.

59 WeIl, Prosper, La crisis del criterio de contrato administrativo, en Revista de Derecho Público 39-40 (1986), p. 163.
} 
Entonces, la noción de servicio público, como ya se ha dicho, se coloca en la base de la elaboración del contrato administrativo y pretende resumir el núcleo esencial de la particularidad del derecho administrativo. En efecto, la doctrina reconoce explícitamente que el criterio del servicio público permite la aplicación de reglas especiales a los contratos administrativos, señalando que "el derecho público francés no aplica pura y simplemente las reglas del derecho privado a los contratos administrativos celebrados para el funcionamiento de los servicios públicos; concilia [¿altera?] estas reglas con la idea fundamental de que ellas no deben contrariar, sino, por el contrario, facilitar el funcionamiento regular y continuo de los servicios públicos" ${ }^{60}$.

La introducción de la idea de servicio público en la definición del contrato administrativo trae como consecuencia que pueda advertirse allí la presencia del núcleo irreductible del poder público; allí, en la institución que surge del encuentro de voluntades de sujetos jurídicamente iguales, el poder público es incapaz de renunciar a su esencia y admite que ella justifica la modulación del régimen de derecho privado que se traduce en las cláusulas exorbitantes, que lo son, justamente, por desapegarse de las soluciones propias del derecho civil.

En buenas cuentas, para concluir, creo que ha podido establecerse que tanto la polémica alemana como la evolución vivida en Francia por la actividad contractual de la Administración admiten ser interpretadas como la búsqueda de aquel elemento que, permitiendo distinguir al contrato administrativo del contrato de derecho civil, justifican la existencia de un régimen jurídico especial al cual someter a la Administración del Estado, esto es, de un derecho administrativo como derecho propio y específico de la Administración Pública.

\section{BIBLIOGRAFÍA}

Bermúdez Soto, Jorge, Derecho Administrativo General (3a ed., Santiago, LegalPublishing, 2014).

CAmpolieti, Federico, Los limites del contrato administrativo, en Contratos administrativos. Culturas y sistemas jurídicos comparados, FERNÁNDEZ RuIZ, Jorge - SANTIAGO SÁnChEZ, Javier (México, Universidad Nacional Autónoma de México, 2007).

De Laubadère, André, Manual de derecho administrativo (Bogotá, Temis, 1984).

Fioravanti, Maurizio, Otto Mayer e la scienza del diritto amministrativo, en Rivista Trimestrale di Diritto Pubblico (1983).

García de EnTerría, Eduardo, La figura del contrato administrativo, en Revista de Administración Pública 41 (1963).

${ }^{60}$ Jèze, Gastón, Los principios... cit. (n. 35), p. 175. 
Huergo Lora, Alejandro, Los contratos sobre los actos y las potestades administrativas (Madrid, Civitas, 1998).

JèZe, Gaston, Principios generales del derecho administrativo (Buenos Aires, Depalma, 1949), III.

Laband, Paul, Das Staatsrecht des Deutschen Reiches (Tübingen, Laupp, 1876), I.

Laband, Paul, Rezension - Theorie des französischen Verwaltungsrechts, en Archiv für öffentliches Recht 2 (1887).

LANGROD, Georges, Administrative contracts: a comparative study, en The American Journal of Comparative Law 4 (1955).

LEDDA, Franco, Il problema del contratto nel diritto amministrativo (Contributo ad uno studio dei c.d. contratti di diritto pubblico) (Torino, Giappichelli, s/d).

Mannori, Luca, -Sord, Bernardo, Storia del diritto amministrativo (4a ed., RomaBari, Laterza, 2006).

Martín-Retortillo Baquer, Sebastián, La institución contractual en el derecho administrativo: en torno al problema de la igualdad de las partes, en Revista de Administración Pública 29 (1959).

Mayer, Otto, Derecho Administrativo Alemán, (trads.) Horacio Heredia y Ernesto Krotoschin (Buenos Aires, Depalma, 1949), I

MaYer, Otto, Deutsches Verwaltungsrecht (Leipzig, Duncker \& Humblot, 1895), I.

MAYER, Otto, Zur Lehre vom öffentlich-rechtlichen Vertrage en Archiv für öffentliches Recht 3 (1888).

MeILÁn GIL, José Luis, Un meeting point de los ordenamientos jurídicos sobre contratación pública en Revista de Administración Pública 198 (2015)

Merlin, Philippe Antoine, Répertoire universel et raisonné de jurisprudence (4a ed., Paris, Garnery, 1812), I.

Moraga Klenner, Claudio, Contratación administrativa (Santiago, Editorial Jurídica de Chile, 2007).

Oelckers Camus, Osvaldo, En torno al concepto de contrato administrativo, en Revista de Derecho Pontificia Universidad Católica de Valparaíso 3 (1979).

SordI, Bernardo, Tra Weimar e Vienna. Amministrazione pubblica e teoria giuridica nel primo dopoguerra (Milano, Giuffrè, 1987).

Sordi, Bernardo, Pubblica amministrazione, negozio, contratto: universi e categorie ottocentesche a confronto, en Diritto Amministrativo, 1995).

Sото KLoss, Eduardo, La contratación administrativa: un retorno a las fuentes clásicas del contrato (a propósito de la distinción contrato administrativo/contrato civil de la Administración), en Revista de Administración Pública 86 (1978).

STOLleIs, Michael, Storia del diritto pubblico in Germania, 1800-1914, (trads.) Cristina Ricca y Stefano Pietropaoli (Milano, Giuffrè, 2014).

VIrga, Pietro, Contratto (dir. amm.), en Enciclopedia del Diritto (Milano, Giuffrè, 1961), IX.

WeIL, Prosper, La crisis del criterio de contrato administrativo en Revista de Derecho Público 39-40 (1986). 
